\title{
SUBSTRATO E ADUBAÇÃO NITROGENADA NA PRODUÇÃO DE MUDAS DE MARACUJAZEIRO AMARELO EM CONDIÇÕES PROTEGIDAS
}

\author{
Rodrigo Takashi Maruki Miyake ${ }^{1}$, José Eduardo Creste $^{1}$, Nobuyoshi Narita ${ }^{2}$, Wellington Eduardo Xavier \\ Guerra $^{1}$ \\ Universidade do Oeste Paulista - UNOESTE, Presidente Prudente, SP ${ }^{1}$. APTA ${ }^{2}$
}

\begin{abstract}
RESUMO
Atualmente, mudas de diversas fruteiras são produzidas no cultivo protegido, com o uso de substratos aliados a adubações. Há necessidade de substrato de fácil aquisição e que proporcione mudas de boa qualidade. Sendo assim, o objetivo deste trabalho foi avaliar diferentes substratos comerciais e doses de nitrogênio sobre o desenvolvimento de mudas de maracujazeiro em condições protegidas. Os tratamentos consistiram de três substratos comerciais (Bioplant ${ }^{\circ}$, Fibra de coco e Vivato ${ }^{\circ}$ ) e quatro doses de nitrogênio (0; 150; 300 e $600 \mathrm{mg} \mathrm{dm}^{-3} \mathrm{~N}$ ). Após 120 dias, avaliou-se a altura de planta, número de folhas, peso da matéria seca de parte aérea (MSPA), raizes (MSR) e total (MST) e o teor de clorofila (SPAD). Na altura das plantas, a Fibra de Coco diferiu significativamente dos demais substratos. A altura máxima de $122 \mathrm{~cm}$ foi obtida na dose de $600 \mathrm{mg} \mathrm{dm}^{-3}$ de $\mathrm{N}$. No número de folhas a Fibra de coco proporcionou a melhor resposta com média de 20 folhas, sendo superiores Bioplant ${ }^{\circ}$ e Vivatto ${ }^{\circ}$. Na MSPA a Fibra de Coco e Bioplant foram superiores em relação ao Vivatto ${ }^{\circ}$, e na avaliação de MST observou-se o acúmulo máximo de $19 \mathrm{~g}$ de matéria seca das mudas na dose de $600 \mathrm{mg} \mathrm{dm}^{-3}$ de $\mathrm{N}$ nas plantas desenvolvidas com Bioplant ${ }^{\circ}$. No teor de clorofila os melhores resultados foram obtidos no substrato Bioplant ${ }^{\circledR}$ com média de valores SPAD de 40 , mas não houve diferença para a Fibra de coco.
\end{abstract}

Palavras-chave: cultivo protegido; nitrogênio; nutrição mineral; Passiflora edulis Sims.

\section{SUBSTRATE AND NITROGEN FERTILIZER ON SEEDLING PRODUCTION OF YELLOW PASSION FRUIT IN PROTECTED CONDITIONS}

\begin{abstract}
Currently, various fruit seedlings are produced in the protected cultivation with the use of appropriate substrates coupled the fertilization. No need of looking for easy acquisition substrate that provides good quality seedlings. Thus, the objective of this work was to evaluate commercial substrate and doses of nitrogen on the development of seedlings of passion of high stature in protected conditions. The treatments consisted of three commercial substrates (Bioplant ${ }^{\circ}$, Coconut Fiber and Vivato ${ }^{\circ}$ ) and four doses of nitrogen (0;150; 300 and $600 \mathrm{mg} \mathrm{dm}^{-3} \mathrm{~N}$ ). After 120 days, evaluated plant height, number of leaves, dry matter weight of shoot (MSPA), root (MSR) and total (MST) and the chlorophyll content (SPAD). In plant height of plants, the Coconut Fiber, differed significantly from other substrates. The maximum height of $122 \mathrm{~cm}$ was obtained at a dose of $506 \mathrm{mg} \mathrm{dm}^{-3} \mathrm{~N}$. The number of leaves the Coconut Fiber has provided the best response with an average of 20 leaves, being superior to the substrate Bioplant and Vivatto ${ }^{\circ}$. On MSPA Coconut Fiber and Bioplant ${ }^{\circ}$ were superior in relationship the Vivatto ${ }^{\circ}$, and evaluation of MST has been observed maximum accumulation of $19 \mathrm{~g}$ of dry matter of seedlings at a dose of $600 \mathrm{mg} \mathrm{dm}^{-3} \mathrm{~N}$ in plants development with Bioplant substrate. On chlorophyll content feature the best results were obtained in the Bioplant substrate with average of SPAD values of 40 , but there was no gap to on Coconut Fiber.
\end{abstract}

Keywords: mineral nutrition; nitrogen; Passiflora edulis Sims; protected cultivation.

\section{INTRODUÇÃO}

O maracujá-amarelo (Passiflora edulis

Sims. f. flavicarpa Deg.), também conhecido como maracujá-azedo, representa aproximadamente $98 \%$ da produção nacional (AGRIANUAL, 2015). 
O sistema de mudas de maracujá proposto à região Oeste de São Paulo viabiliza economicamente a cultura, ao permitir a convivência com viroses que normalmente ocorrem na cultura. No sistema de produção tradicional as mudas são levadas para o campo com cerca de $30 \mathrm{~cm}$ de altura nos meses de março/abril, coincidindo com o período de produção da safra anterior. Ou seja, este fato predispõe a infecção precoce da planta, que resulta em queda de produtividade e qualidade do fruto. No novo modelo proposto, que considera o desenvolvimento de mudas em viveiros protegidos, faz com que as mudas sejam levadas para o campo com mais de $1,8 \mathrm{~m}$ de altura em agosto, após a colheita e a eliminação da cultura anterior. A ideia é quebrar o ciclo da doença.

A produção de mudas em ambiente protegido tem por finalidade garantir 0 desenvolvimento de uma planta com qualidade, em curto período de tempo, e baixo custo (CUNHA et al., 2005). Atualmente, mudas de diversas fruteiras vêm sendo produzidas em sacolas plásticas, em sistemas protegidos e com o uso de substratos adequados a esse tipo de produção. O cultivo de plantas em substratos permite o controle mais rígido da nutrição mineral e da irrigação de forma a proporcionar melhores condições de crescimento para as plantas (GRASSI FILHO; SANTOS, 2004).

A utilização do nitrogênio para produção de mudas em recipientes tem apresentado bons resultados na formação de mudas de maracujazeiro (MENDONÇA et al., 2007). Neste contexto, a prática de adubações, além de se constituir num fator indispensável para o desenvolvimento das mudas, acelera consideravelmente o crescimento, reduzindo os custos de produção.

A eficiência da adubação em cobertura depende basicamente das doses e fontes dos adubos utilizados, da capacidade de troca catiônica e das características físicas do substrato. Uma das alternativas para aumentar a eficiência dessas adubações seria a realização de vários parcelamentos, para que as mudas possam ser transplantadas ao campo, com cerca de 120 dias (MENDOÇA et al., 2007).

Silva et al. (2010) na avaliação de diferentes composições de substratos para a produção de mudas de maracujazeiro amarelo concluíram que os melhores resultados foi substrato que continha esterco bovino. Provavelmente isso se deve não apenas ao fornecimento de nutrientes contido nele, mas também à melhoria de outros constituintes de fertilidade do solo e aeração, no fornecimento de água, entre outros. Silva et al. (2001) estudando diferentes substratos em mudas de maracujazeiro verificaram que 0 substrato Plantmax proporcionou valores mais elevados que a Vermiculita para todas as características analisadas e concluiu que este resultado foi devido à composição química do Plantmax , que possui teores mais elevados de nutrientes do que a Vermiculita ${ }^{\circ}$, principalmente $\mathrm{N}, \mathrm{P}, \mathrm{K}, \mathrm{Ca}$ e $\mathrm{Mg}$.

Prado et al. (2004) e Natale et al. (2006) trabalhando com nitrogênio concluíram que a adubação nitrogenada resultou em maior desenvolvimento das mudas de maracujazeiro amarelo, além de melhor nutrição e maior produção de matéria seca.

Deste modo, este trabalho teve como objetivo estudar o efeito de diferentes tipos de substratos comerciais e de doses de nitrogênio no desenvolvimento de mudas de maracujazeiro em condições protegidas.

\section{MATERIAL E MÉTODOS}

O trabalho foi realizado em estufa na área experimental pertencente à APTA (Agência Paulista de Tecnologia dos Agronegócios) localizada no município de Presidente Prudente na região Oeste do Estado de São Paulo, cujas coordenadas geográficas são: Latitude 220 07'04" e longitude $51023^{\prime} 01^{\prime \prime}$ no período de maio a setembro de 2010.

A estufa coberta por filme plástico transparente foi revestida nas laterais com tela anti-afídeos, para impedir a entrada de afídeos e foi coberta no interior com sombrite $50 \%$. As bancadas foram dispostas $80 \mathrm{~cm}$ acima do solo.

No experimento utilizou-se delineamento inteiramente casualizado, com 12 tratamentos e com 5 repetições, em esquema fatorial $3 \times 4$, totalizando 60 parcelas experimentais. Os tratamentos foram três substratos comerciais (Bioplant, Fibra de coco e Vivatto ${ }^{\circ}$ ) e quatro doses de nitrogênio (zero; 150; 300 e $600 \mathrm{mg} \mathrm{dm}$ ${ }^{3}$ de $N$ ) aplicado na forma de ureia $(45 \% \mathrm{~N})$. As parcelas experimentais foram compostas por uma planta (1 por sacola plástica). Os substratos foram submetidos a análises químicas e físicas no laboratório de solos (Tabela 1 e 2 ), respectivamente. 
Tabela 1. Composição química dos substratos comerciais. Presidente Prudente- SP, 2010.

\begin{tabular}{lccccccc}
\hline Substrato & $\mathrm{pH}$ & $\mathrm{MO}$ & $\mathrm{Ca}$ & $\mathrm{Mg}$ & $\mathrm{S}$ & $\mathrm{K}$ & $\mathrm{P}$ \\
\hline \multicolumn{7}{c}{$\left(\mathrm{CaCl}_{2}\right)$} & \multicolumn{5}{c}{$\mathrm{mg} \mathrm{dm}^{-3}$} \\
\hline Bioplant $^{8}$ & 5,0 & 218 & 440 & 144 & 193 & 652 & 230 \\
Fibra de coco $^{8,0}$ & 121 & 240 & 48 & 154 & 936 & 104 \\
Vivatto $^{8}$ & 4,8 & 123 & 380 & 264 & 234 & 480 & 230 \\
\hline
\end{tabular}

Tabela 2. Características físicas dos substratos comerciais Presidente Prudente- SP, 2010.

\begin{tabular}{lllllll}
\hline Substrato & $\mathrm{pH}\left(\mathrm{CaCl}_{2}\right)$ & $\mathrm{CRA}$ & Densidade $\left(\mathrm{Kg} \mathrm{m}^{-3}\right)$ & $\mathrm{CE}\left(\mathrm{dS} \mathrm{m}^{-1}\right)$ & $\mathrm{U}(\%)$ & $\mathrm{PT}$
\end{tabular}

\begin{tabular}{lllrlll}
\hline Bioplant $^{8}$ & 5,0 & $38 \%$ & 280 & 1,7 & 65 & $62 \%$ \\
Fibra de coco $^{2}$ & 5,0 & $30 \%$ & 92 & 0,2 & 45 & $95 \%$ \\
Vivatto $^{8}$ & 4,8 & $40 \%$ & 260 & 0,5 & 48 & $90 \%$ \\
\hline
\end{tabular}

Obs. CRA- Capacidade de retenção de água; CE- Condutividade elétrica; U- \% de umidade do substrato e PT- Porosidade total.

As sementes de maracujá amarelo foram da cv. Sul-Brasil afruvec. As sementes de frutos colhidos em plantações comerciais da região foram colocadas para germinar em bandejas de isopor de 200 divisões. Após a germinação das plântulas elas foram transplantadas para sacolas plásticas de 2 litros de polietileno e preenchidas com os substratos comerciais.

As mudas foram tutoradas e conduzidas por meio de estacas de capim napier. Durante o desenvolvimento inicial das mudas cada sacola plástica recebeu $50 \mathrm{ml}$ de água por planta/dia e, com o desenvolvimento das mudas cada sacola passou a receber $100 \mathrm{ml}$ de água por planta/dia de acordo com a capacidade de campo do substrato até a conclusão do experimento.

O fósforo total foi misturado com o substrato por ocasião do enchimento das sacolas e aplicado e o potássio aplicado parcelado em quatro aplicações em cobertura, sendo $20 \%$ da dose no transplante, $30 \%$ após 20 dias, $30 \%$ após 40 dias e $20 \%$ após 60 dias. A adubação nitrogenada foi realizada com a ureia ( $45 \%$ de N). O nitrogênio foi aplicado via fertirrigação e parcelado, com intervalo de 15 dias a partir do transplante das mudas, sendo $10 \%$ aplicado no transplante e mais seis aplicações de $15 \%$ a cada 15 dias.

A unidade experimental analisada foi constituída por uma sacola plástica com capacidade para 2 litros, empregando-se $2 \mathrm{dm}^{-3}$ de substrato por sacola. No transplante, cada sacola recebeu adubações com $\mathrm{P}\left(450 \mathrm{mg} \mathrm{dm}^{-3}\right)$,
$\mathrm{K}\left(300 \mathrm{mg} \mathrm{dm}^{-3}\right), \mathrm{B}\left(0,5 \mathrm{mg} \mathrm{dm}^{-3}\right)$ e $\mathrm{Zn}\left(5 \mathrm{mg} \mathrm{dm}^{-3}\right)$. Como fonte de $P, K, B$ e $Z n$, foram utilizados os fertilizantes químicos: superfosfato triplo, cloreto de potássio, ácido bórico e sulfato de zinco, respectivamente.

Aos 120 dias foi realizada a avaliação dos tratamentos coletando-se dados sobre os seguintes parâmetros: altura de planta (ALT); número de folhas (NF); peso da matéria seca da parte área (MSPA) e peso da matéria seca das raízes (MSR) e peso da matéria seca total (MST) e o teor de clorofila (SPAD). Para coletas dos dados foi utilizado o sistema destrutivo da muda.

Os dados de altura de planta foram avaliados considerando a distância entre o colo até o ápice da folha mais alta, com utilização de régua graduada $(\mathrm{cm})$. Os teores de matéria seca das plantas foram quantificados após as coletas e secagem dos materiais em estufa com circulação de ar forçada a $65^{\circ} \mathrm{C}$ por $72 \mathrm{~h}$ até atingirem o peso constante. Em seguida foram determinadas as biomassas da parte aérea e radicular em balança de precisão analítica $(0,0001)$ e na matéria seca total foi realizado o somatório das biomassas da parte aérea e raízes. O teor de clorofila foi determinado diretamente por um clorofilômetro digital (Chlorophyll Content Meter, CCM-200, OptSciences), sendo considerada a leitura das 3 folhas expandidas do terço médio de cada planta.

Os dados foram submetidos à análise de variância pelo teste de $F(p<0,05)$, e o efeito significativo de cada fator ou da interação foi 
estudado mediante o teste de Tukey $(p<0,05)$, para o tipo de substrato, e mediante regressão, no caso das doses de nitrogênio utilizando o programa computacional Sistema para Análise de Variância - SISVAR (FERREIRA, 1998).

\section{RESULTADOS E DICUSSÃO}

Houve interação das doses de nitrogênio e do tipo de substrato sobre todas as variáveis analisadas: altura de planta (ALT), número de folhas por planta (NF), peso da matéria seca da parte área (MSPA), raízes (MSR), matéria seca total (MST) e o teor de clorofila (SPAD).

Em relação às doses de nitrogênio, observou-se um comportamento linear sobre a MSPA e MST (Figura 1), ou seja, à medida que se aumentou a dose de $\mathrm{N}$ ocorreu aumento da matéria seca das plantas de maracujazeiro. Obtiveram-se os melhores resultados para o substrato Fibra de Coco e Bioplant na dose máxima de $600 \mathrm{mg} \mathrm{dm}^{-3} \mathrm{de} \mathrm{N}$. O mesmo efeito na MSPA foi constatado por Natale et al. (2006), onde com as doses mais altas de $\mathrm{N}$ obteve-se a produção máxima (16 g vaso) para a dose de 362 $\mathrm{mg} \mathrm{dm^{-3 }}$ de N. Porém o substrato Fibra de Coco não foi superior estatisticamente ao Bioplant na produção da matéria seca de parte área. Este fato pode ser atribuído possivelmente ao bom nível de nutrientes de potássio e fósforo presentes nos dois substratos (Tabela 2) o que influenciou diretamente no desenvolvimento da parte área.
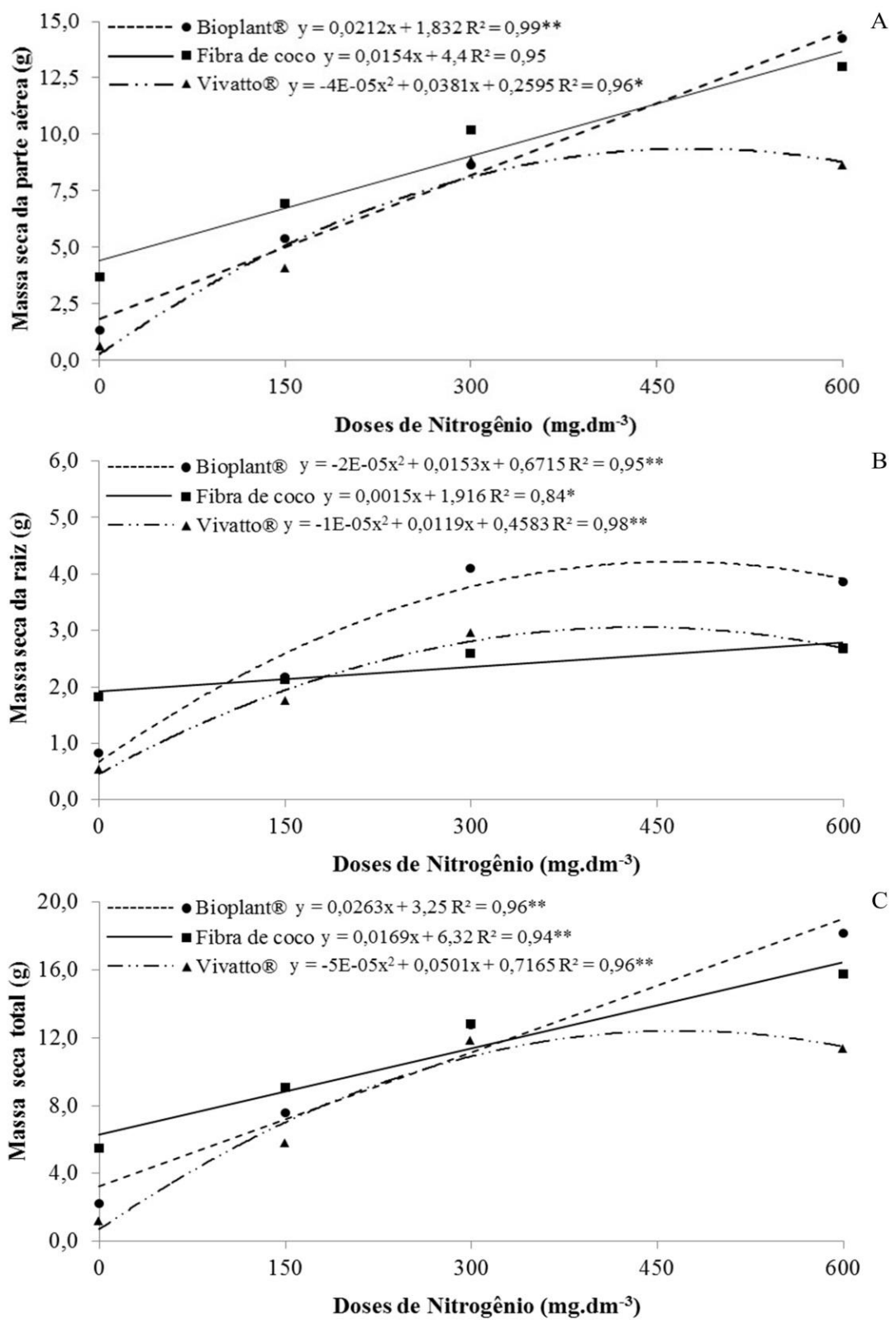

Figura 1. Equações de regressão para (A) Matéria seca da parte aérea (g), (B) Matéria seca de raiz (g) e (C) Matéria seca total (g) de plantas de maracujazeiro em função da dose de nitrogênio aplicada, aos 120 dias.

** Modelo matemático significativo a $1 \%$ de probabilidade pelo teste $\mathrm{F}$. 
Os resultados lineares observados na MSPA para os substratos Biolpant e Fibra de coco diferem do verificado por Caproni et al. (2013) na produção de mudas de maracujazeiro amarelo, que constataram que as doses de nitrogênio apresentaram efeito quadrático sobre a variável de MSPA com máxima resposta de 1,21 g quando recebeu a dose $1944,77 \mathrm{mg} \mathrm{dm}^{-3}$ de $\mathrm{N}$ aos 120 dias.

A resposta do substrato comercial Vivatto ${ }^{\circ}$ diferiu dos demais substratos, onde se observou comportamento quadrático em resposta às doses mais altas de nitrogênio, se levando a concluir que o melhor resultado para característica de MSPA foi constatada na dose de $381 \mathrm{mg} \mathrm{dm}^{-3}$ de $\mathrm{N}$, a partir desta dose ocorreram perdas de matéria seca das plantas, devido ao possível efeito tóxico do nutriente considerandose 0 substrato Vivatto ${ }^{\circ}$. Comportamento semelhante foi visto por Caproni et al. (2013) na produção de mudas de maracujá amarelo trabalhando com dois tipos de substrato, contudo a dose máxima que proporcionou o efeito quadrático na MSPA foi de $2194,32 \mathrm{mg} \mathrm{dm}^{-3} \mathrm{de} \mathrm{N}$.

Segundo Malavolta e Neptune (1983), a utilização de adubos "fisiologicamente ácidos" como a ureia, contendo $\mathrm{N}$ na forma $\mathrm{N}-\mathrm{NH} 2$, reduz o $\mathrm{pH}$ do solo, aumenta a disponibilidade e consequentemente a absorção de micronutrientes, podendo levá-los a atingir níveis tóxicos às plantas.

Na variável de massa seca de raiz (Figura 1) o substrato Bioplant apresentou a melhor resposta à aplicação de nitrogênio na dose 350

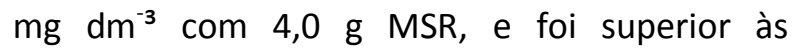
respostas obtidas pelos demais substratos estudados. Este resultado pode ser explicado pelo fato do substrato Bioplant apresentar (Tabela 2) a maior porcentagem de umidade em relação aos outros substratos, além de níveis adequados de cálcio e fósforo, e maior concentração de matéria orgânica na sua composição química (Tabela 1) proporcionando melhor absorção de água e nutrientes pelas mudas, refletindo no melhor desenvolvimento radicular das plantas. Esta resposta difere de Mendonça et al. (2007), os quais estudando doses de nitrogênio e fósforo em mudas de maracujazeiro verificaram comportamento linear da MSR e a melhor resposta $(6,23 \mathrm{~g})$ sendo obtida somente com a maior dose do fertilizante.

A fibra de coco mostrou-se ser o melhor substrato sem aplicação de nitrogênio, com média de $2 \mathrm{~g}$ por planta na matéria seca de raiz, em decorrência da boa característica física do substrato, como a menor densidade e maior porosidade total. Contudo, quando se aplicou as doses de $\mathrm{N}$ não houve resposta positiva no aumento de volume das raízes das mudas de maracujazeiro, como se observou nos outros substratos. Possivelmente o maior volume de macroporos presentes no substrato (Tabela 2) favorece a lixiviação dos nutrientes, o que diminuiu o potencial de desenvolvimento do sistema radicular das plantas e consequentemente, acarretou em menor valor da MSR.

O substrato Vivatto ${ }^{\circ}$ foi superior a Fibra de Coco, mas apresentou menor resposta no peso seco de raízes do que o substrato Bioplant ${ }^{\circ}$ quando se aumentou as doses de N. A menor concentração de matéria de orgânica, cálcio e potássio no substrato pode explicar o desenvolvimento inferior das raízes das mudas, quando comparados as mudas desenvolvidas no substrato Bioplant ${ }^{\circ}$.

$\mathrm{Na}$ avaliação aos 120 dias, observou-se um acúmulo máximo de $19 \mathrm{~g}$ (Figura 1) na característica de matéria seca total das mudas de maracujazeiro em resposta a dose de $600 \mathrm{mg} \mathrm{dm}$ 3 de $\mathrm{N}$ nas mudas desenvolvidas no substrato Bioplant ${ }^{\circ}$. Conforme se verifica na matéria seca total (Figura 1) à medida que se aumentou as doses de $\mathrm{N}$ resultou no acúmulo diretamente proporcional ao aumento das doses de nitrogênio. Comportamento semelhante foi verificado na Fibra de coco, onde se obteve $16 \mathrm{~g}$ de MST na dose máxima fornecida de nitrogênio. Contudo, as mudas desenvolvidas no substrato Vivatto ${ }^{\circ}$, apresentaram comportamento contrário aos outros substratos avaliados, onde se constatou uma curva quadrática. A partir da dose $370 \mathrm{mg} \mathrm{dm}^{-3}$ de $\mathrm{N}$, ocorreu queda no acúmulo de matéria de seca total. Este fato poderia ser explicado pela salinização provocada pela ureia e diminuição do $\mathrm{pH}$ do substrato e toxidez dos micronutrientes. Estes resultados diferem dos observados em Silva et al. (2010), onde não se encontraram respostas significativas para a MST em mudas de maracujazeiro amarelo desenvolvidas em substratos de solo puro, solo + superfosfato simples, solo + esterco e Plantmax .

Para a variável altura (Figura 2), obtevese a resposta máxima de $122 \mathrm{~cm}$ na dose máxima de $600 \mathrm{mg} \mathrm{dm}^{-3}$ de $\mathrm{N}$ quando utilizou-se a Fibra de coco. Este resultado mostrado na variável altura de planta é devido às características físicas do substrato (Tabela 2), que possui baixa 
densidade 0 que poderia ter facilitado 0 desenvolvimento das raízes, junto com boa porosidade total. 0 substrato Bioplant ${ }^{\circ}$ apresentou resposta linear semelhante à Fibra de Coco na variável de altura de planta, mas foi inferior a ela. Essa diferença proporcionada na característica de altura entre os substratos Fibra de Coco e Bioplant ${ }^{\circ}$ deve-se a diferença de condutividade elétrica (CE) dos substratos. A Fibra de Coco apresenta baixa CE, sendo ideal para produção de mudas, que geralmente são mais sensíveis a salinidade do que as plantas adultas. E já o substrato Bioplant possui a maior CE dos três substratos estudados, podendo ter influenciado o potencial de desenvolvimento das mudas.

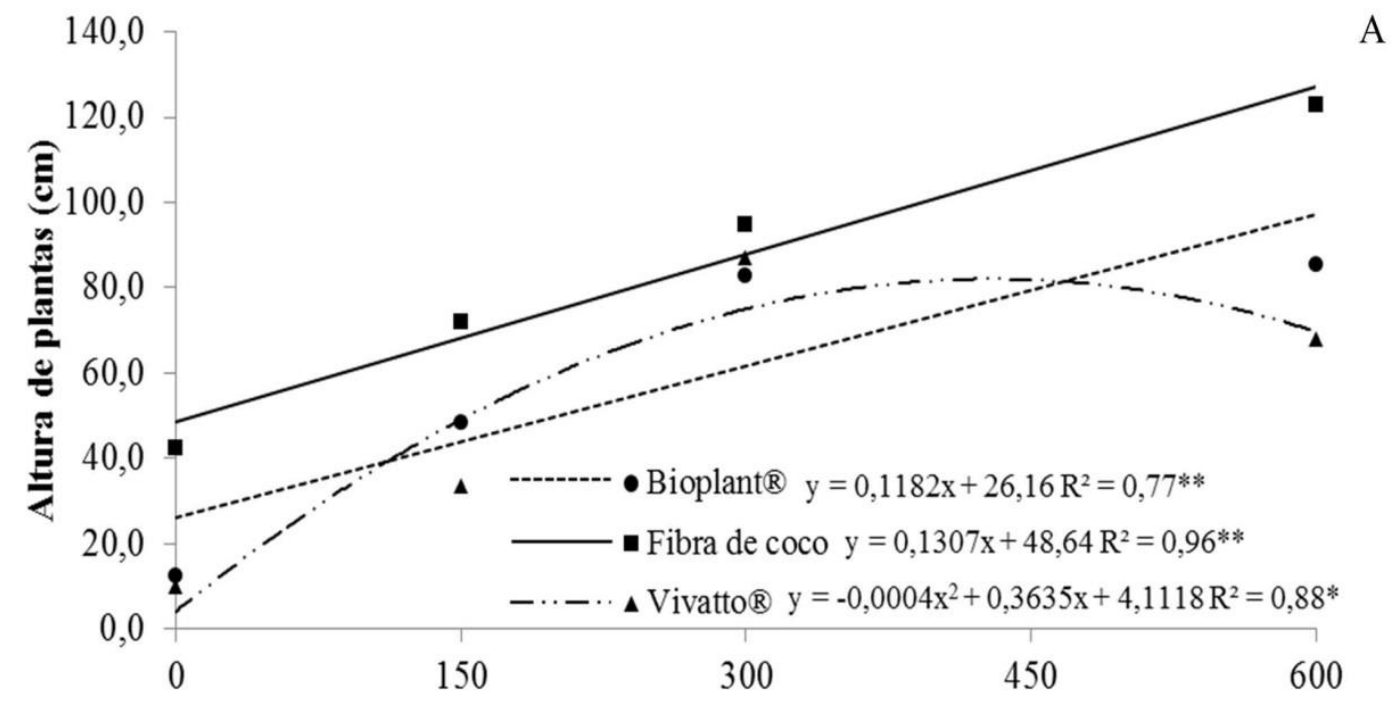

Doses de Nitrogênio $\left(\mathrm{mg}^{-\mathrm{dm}^{-3}}\right)$

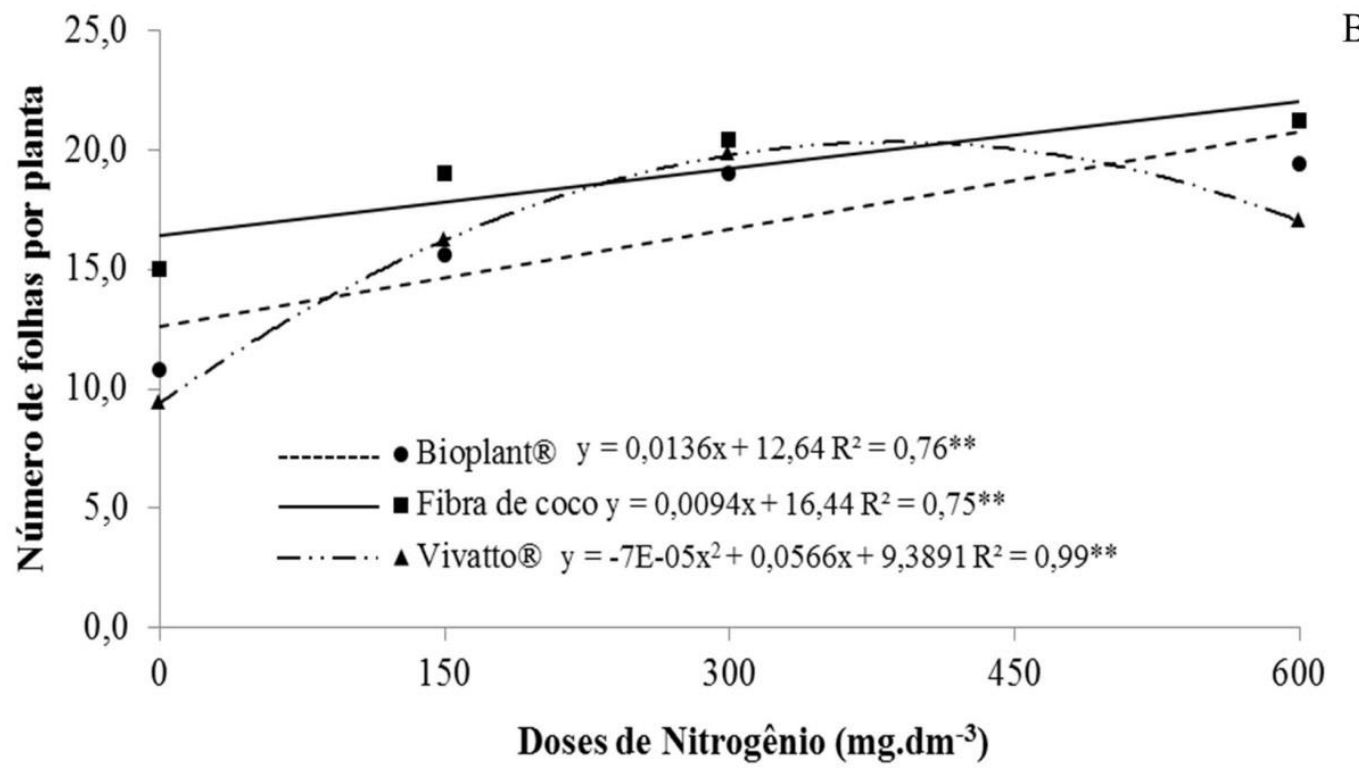

Figura 2. Equações de regressão para $(A)$ altura de planta $(\mathrm{cm}),(B)$ número de folhas por planta de plantas de maracujazeiro em função da dose de nitrogênio aplicada, aos 120 dias. ** Modelo matemático significativo a $1 \%$ de probabilidade pelo teste $\mathrm{F}$.

Na variável altura (Figura 2), quando se utilizou o substrato Vivatto se verificou que as doses de $\mathrm{N}$ proporcionaram uma resposta quadrática, obtendo-se a altura máxima de 86,69 $\mathrm{cm}$ na dose máxima de $454,37 \mathrm{mg} \mathrm{dm}^{-3}$ de $\mathrm{N}$. Este resultado mostrado na variável altura de planta, evidencia que houve algum problema com o substrato Vivatto ${ }^{\circ}$, já que a melhor resposta observada do mesmo para característica, foi inferior as respostas apresentadas pelos outros substratos comerciais avaliados.

Como pode ser observado houve resposta linear da Fibra de coco e do Bioplant em relação ao número de folhas (NF) (Figura 2), 
onde os melhores resultados foram observados na dose máxima de nitrogênio nas plantas de maracujazeiro aos 120 dias, $\left(600 \mathrm{mg} \mathrm{dm}^{-3} \mathrm{~N}\right)$. Embora a característica de NF, quando avaliada isoladamente não signifique uma resposta importante na questão de qualidade das mudas, porém, quando ela é combinada à altura da muda e a matéria de seca é uma excelente característica no padrão da análise de qualidade de mudas, ou seja, quanto maior, melhor nutrida está a planta. Resultado semelhante foi encontrado por Natale et al. (2006), cujo ponto máximo foi de 16 folhas, na dose próxima de 385 $\mathrm{mg} \mathrm{dm}{ }^{-3}$ de $\mathrm{N}$.

As mudas cultivadas no substrato Fibra de Coco apresentaram melhor resultado no número de folhas, com média de 21,20 folhas, possivelmente influenciado pelo bom nível de potássio $(\mathrm{K})$ presente no substrato (Tabela 1 ) que é fundamental no metabolismo e acúmulo de matéria seca (MALAVOLTA, 2006). Com relação ao substrato Vivatto ${ }^{\circ}$, se verificou uma resposta quadrática as doses de $\mathrm{N}$. O melhor resultado observado na característica foi de 20,8 folhas por planta na dose estimada de $404,28 \mathrm{mg} \mathrm{dm}^{-3}$ de $\mathrm{N}$, após esta dose houve um decréscimo do número de folhas.

Para o teor clorofila (Figura 3) o substrato Bioplant proporcionou o maior valor SPAD (40) e diferiu significativamente do substrato Vivatto ${ }^{\circ}$ na dose $600 \mathrm{mg} \mathrm{dm}^{-3} \mathrm{~N}$. Em todos os substratos avaliados houve resposta linear para as diferentes doses utilizadas, ou seja, o aumento das doses de $\mathrm{N}$ resultou em maior teor de clorofila nas folhas. Nos substratos Bioplant ${ }^{\circledR} \mathrm{e}$ Fibra de coco observaram-se respostas semelhantes no valor SPAD (40 e 35) para o teor de clorofila.

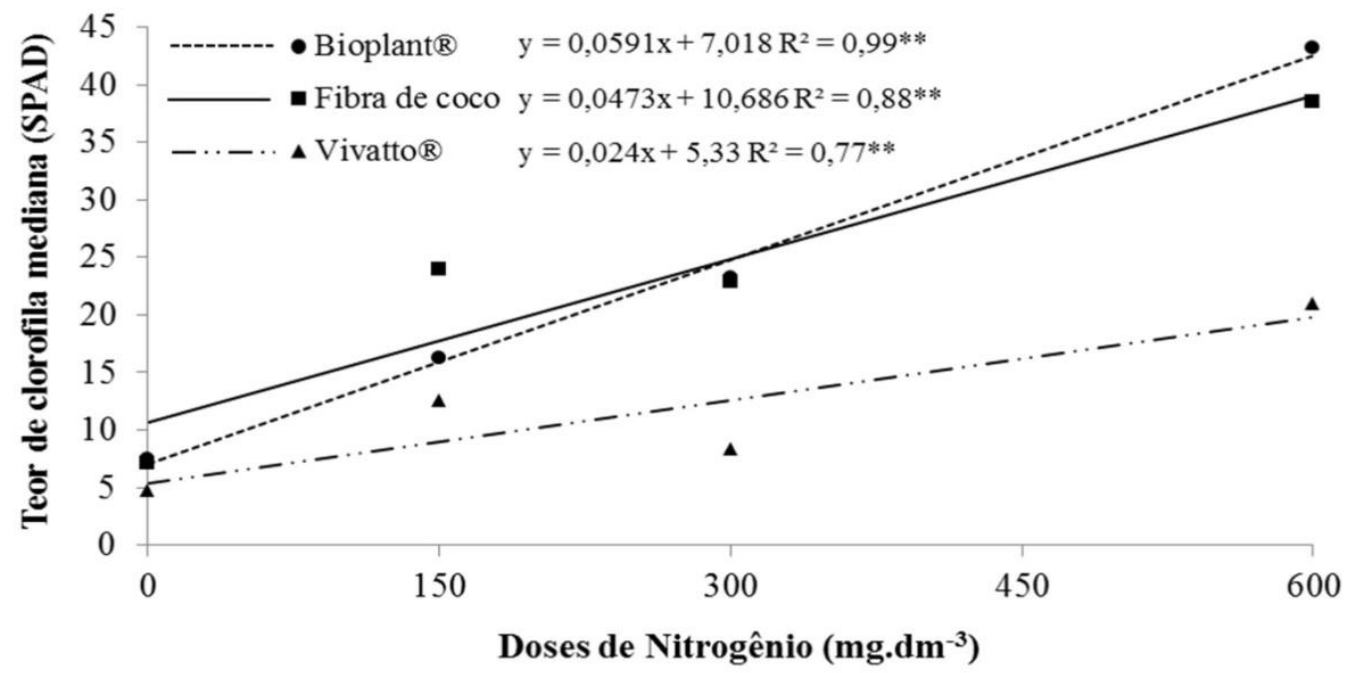

Figura 3. Equações de regressão para teor de clorofila mediana (SPAD) de plantas de maracujazeiro em função da dose de nitrogênio aplicada, aos 120 dias. ${ }^{* *}$ Modelo matemático significativo a $1 \%$ de probabilidade pelo teste $\mathrm{F}$.

O tratamento Fibra de coco mostrou valores SPAD muito superior ao substrato Vivatto ${ }^{\circ}$, a partir de $300 \mathrm{mg} \mathrm{dm}^{-3}$ pode ser devido à maior concentração de $\mathrm{Mg}$ presente na composição da Fibra de coco (Tabela 1), o que se refletiu no teor clorofila, já que o $\mathrm{N}$ e o $\mathrm{Mg}$ juntos são os dois nutrientes constituintes da molécula de clorofila presentes nas folhas, responsável pelo aspecto da coloração esverdeada comum as plantas.

A medida do teor de clorofila é muito interessante na avaliação de qualidade das mudas, pois se pode correlacioná-lo com o teor de nitrogênio foliar das plantas, ou seja, quanto maior os valores do teor de clorofila, mais nitrogênio as plantas têm na sua composição, e melhor a qualidade das mudas de maracujazeiro amarelo, até certos limites.

Vários autores têm relatado à viabilidade da avaliação indireta de clorofila como indicativo do estado nutricional das plantas em relação ao $\mathrm{N}$ (FURLANI JÚNIOR et al., 1996; CARVALHO et al., 2003). Santos et al. (2011) avaliando diferentes fontes de nitrogênio (sulfato de amônio, nitrato de amônio e ureia) no crescimento inicial de plantas de maracujazeiro amarelo, observou-se que as plantas, apresentaram valores muito 
próximos com valores SPAD de 56,36; 57,17 e 59,02 para o teor de clorofila.

\section{CONCLUSÕES}

$\mathrm{Na}$ produção de mudas em condições protegidas os substratos comerciais Bioplant ${ }^{\circ} \mathrm{e}$ Fibra de coco proporcionaram os melhores resultados no desenvolvimento das plantas de maracujazeiro amarelo.

\section{REFERÊNCIAS}

AGRIANUAL 2015: Anuário da agricultura brasileira. São Paulo: FNP Consultoria e Comércio, 2015.

CAPRONI, C. M.; RAMOS, J. D.; VIEIRA NETO, J.; SILVA, L. F. O.; SIMÕES, J. C.; PEREIRA, W. R. Substratos e adubação nitrogenada na produção de mudas de maracujazeiro amarelo. Sentia Agrária, n.14, p.69-75, 2013. https://doi.org/10.5380/rsa.v14i2.40932

CARVALHO, M. A. C.; FURLANI JÚNIOR, E.; ARF, O.; SÁ, M. E.; PAULINO, H. B.; BUZETTI, S. Doses e épocas de aplicação de nitrogênio e teores foliares deste nutriente e de clorofila em feijoeiro. Revista Brasileira de Ciência do Solo, v.27, p.445-450, 2003. https://doi.org/10.1590/S0100-

$\underline{06832003000300006}$

CUNHA, A. O.; ANDRADE, L. A.; BRUNO, R. L. A.; SILVA, J. A. L.; SOUZA, V. C. Efeitos de substratos e das dimensões dos recipientes na qualidade das mudas de Tabebuia impetiginosa (Mart. Ex D.C.) Standl. Revista Árvore, n.29, p.507-516, 2005. https://doi.org/10.1590/S0100$\underline{67622005000400002}$

FERREIRA, D. F. Sisvar - Sistema de análise de variância para dados balanceados. Lavras: UFLA, 1998.

FURLANI JÚNIOR, E.; NAKAGAWA, J.; BULHOES, L. J.; MOREIRA, J. A. A.; GRASSI FILHO, H. Correlação entre leituras de clorofila e níveis de nitrogênio aplicados em feijoeiro. Bragantia, n.55, p.171175, 1996. https://doi.org/10.1590/S0006$\underline{87051996000100022}$

GRASSI FILHO, H.; SANTOS, C. H. Importância da relação entre os fatores hídricos e fisiológicos no desenvolvimento de plantas cultivadas em
Os melhores resultados observados em resposta à adubação nitrogenada para altura de planta, matéria seca de parte aérea e total, número de folhas e teor de clorofila no desenvolvimento das mudas de maracujazeiro amarelo em condições protegidas foram obtidos na dose de $600 \mathrm{mg} \mathrm{dm}^{-3}$ de N.

substratos. In: BARBOSA, J. G., MARTINEZ, H. E. P., PEDROSA, M. W.; SEDIYAMA, M. A. Nutrição e adubação de plantas cultivadas em substrato. Viçosa: UFV, 2004. p. 190-225.

MALAVOLTA, E. Manual de nutrição mineral de plantas. São Paulo: Agronômica Ceres, 2006.

MALAVOLTA, E.; NEPTUNE, A. M. L. Características e eficiência dos adubos nitrogenados. São Paulo: Centro de Pesquisa e Promoção de Sulfato de Amônio, 1983.

MENDONÇA, V.; FERREIRA, E. A.; PAULA, Y. C. M.; BATISTA, T. M. V.; RAMOS, J. D. Crescimento de mudas de maracujazeiro-amarelo influenciado por doses de nitrogênio e de superfosfato simples. Revista Caatinga, n.20, p.137-143, 2007.

NATALE, W.; PRADO, R. M.; ALMEIDA, E. V.; BARBOSA, J. C. Adubação nitrogenada e potássica no estado nutricional de mudas de maracujazeiro-amarelo. Acta Scientiarum, n.28, p.187-192, 2006. https://doi.org/10.4025/actasciagron.v28i2.1036

PRADO, R. M.; BRAGHIROLLI, L. F.; NTALE, W.; CORRÊA, M. C. M.; ALMEIDA, E. V. Aplicação de potássio no estado nutricional e na produção de matéria seca de mudas de maracujazeiroamarelo. Revista Brasileira Fruticultura, n.26, p.295-299, 2004. https://doi.org/10.1590/S0100$\underline{29452004000200028}$

SANTOS, P. C.; LOPES, L. C.; FREITAS, S. J.; SOUSA, L. B.; CARVALHO, A. J. C. Crescimento inicial e teor nutricional do maracujazeiro amarelo submetido à adubação com diferentes fontes nitrogenadas. Revista Brasileira Fruticultura, n.33, p.722-728, 2011. https://doi.org/10.1590/S0100$\underline{29452011000500101}$

SILVA, R. P.; PEIXOTO, J. R.; JUNQUEIRA, N. T. V. Influência de Diversos substratos no 
desenvolvimento de mudas de maracujazeiro azedo (Passiflora edulis Sims f. flavicarpa DEG). Revista Brasileira Fruticultura, n.23, p.377-381, 2001.

https://doi.org/10.1590/S0100$\underline{29452001000200036}$

SILVA, E. A.; MARUYAMA, W. I.; MENDOÇA, V.; FRANCISCO, M. G. S.; BARDIVIESSO, D. M.; TOSTA, M. S. Composição de substratos e tamanho de recipiente na produção e qualidade das mudas de maracujazeiro amarelo. Ciência e Agrotecnologia, n.34, p.588-595, 2010. https://doi.org/10.1590/S1413-

$\underline{70542010000300009}$

Recebido para publicação em 14/03/2016

Revisado em 27/01/2017

Aceito em 07/06/2017 